\title{
Peculiar Vulnerability to Nicotine Oral Self-administration in Mice during Early Adolescence
}

\author{
Walter Adriani, Simone Macrì, Roberta Pacifici, and Giovanni Laviola
}

A "gateway" function toward substance abuse has been suggested for early tobacco smoking. Nicotine actually represents an easily available drug for human adolescents, who are very likely to use a number of different psychoactive agents. Surprisingly, the psychobiological factors involved in this age-related willingness have been poorly investigated. In Experiment 1, nicotine consumption was studied in outbred CD-1 mice during Early (postnatal day (pnd) 24 to 35), Middle (pnd 37 to 48) or Late (pnd 50 to 61) adolescence, in an oral self-administration paradigm. During the drinking session ( $2 \mathrm{~h} /$ day), animals had free choice between either tap water or a nicotine solution (10 $m g / l)$. After a 6-day period, a fading study was carried out, in which nicotine concentration was reduced to $7 \mathrm{mg} / \mathrm{l}$ (days 7-9) and $5 \mathrm{mg} / \mathrm{l}$ (days 10-12), to assess whether animals would compensate by increasing their intake from the nicotine solution. In Experiment 2, psychopharmacological effects on locomotion induced by the nicotine solution $(0,10$, $30 \mathrm{mg} / \mathrm{l})$ during the 1-h drinking session were assessed in Early and Late adolescent mice. In Experiment 1, Early adolescents expressed a marked and stable preference for the nicotine solution, showing a daily nicotine intake of $1.15 \pm$
$0.04 \mathrm{mg} / \mathrm{kg}$. Middle adolescents did not show any preference for either bottle, whereas a tendency toward avoidance for the nicotine solution was found for Late adolescents. In the fading study, Early adolescents were the only group to show increased consumption from the nicotine bottle as far as nicotine concentration was reduced. A time-course analysis of plasma levels of cotinine (the principal biomarker of nicotine consumption) revealed some pharmacokinetic differences between the three age-groups. In Experiment 2, drinking from a nicotine solution produced a prominent hyperactivity in Early adolescents, whereas a quite opposite profile was associated with older subjects. In summary, even if a role for taste factors cannot be completely ruled out, a peculiar spontaneous drive toward oral nicotine consumption, as well as a nicotine-induced arousal, is specific to Early adolescence in mice. The present animal model might be useful to investigate psychobiological determinants involved in early tobacco smoking in human adolescents

[Neuropsychopharmacology 27:212-224, 2002] (C) 2002 American College of Neuropsychopharmacology. Published by Elsevier Science Inc.
From the Behavioural Pathophysiology Section, Lab F.O.S. (WA, $\mathrm{SM}, \mathrm{GL}$ ) and Lab Biochimica Clinica (RP), Istituto Superiore di Sanità, viale Regina Elena 299, I-00161 Roma, Italy.

Address correspondence to: G. Laviola, Behavioural Pathophysiology Section, Lab F.O.S., viale Regina Elena 299, I-00161 Roma, Italy. Tel: +39-06-4990-2105; Fax: +39-06-495-7821, E-mail: Laviola@ iss.it

Received June 25, 2001; revised January 9, 2002; accepted January 21, 2002.

Online publication: $1 / 22 / 02$ at www.acnp.org/citations/ Npp012202233.
KEY WORDS: Nicotine; Oral self-administration; Free-choice drinking; Adolescence; Mice

Recent research has emphasized that adolescence is associated with patterns of temporary deviance (Arnett 1992) and the use of various kinds of psychoactive agents (Mathias 1996). Drug abuse in adolescents ranging from 11-12 to 17-18 years of age is likely to start with tobacco smoking, which can be followed by marijuana and/or 
alcohol, and eventually psychostimulants as well as opiate drugs (see Yamaguchi and Kandel 1984). The age of first encounter with these psychoactive compounds appears to be critical, since it influences subsequent patterns of drug-related behavior. Indeed, a higher probability of shifting from use to abuse and chance to develop dependence appears to be associated with an early approach to drugs (Robins and Przybeck 1985; Anthony and Petronis 1995; for tobacco smoking, see Taioli and Wynder 1991; Breslau et al. 1993; Nides et al. 1995; Kandel and Chen 2000). Despite the social and scientific importance of deepening our knowledge of this issue (see e.g. Colby et al. 2000), there have been very few investigations on the psychobiological factors contributing to the specific adolescence-related willingness to experience various psychoactive drugs (for a review, see Laviola et al. 1999; Spear 2000).

For the purpose of laboratory studies, a suitable animal model of human adolescence is available in rodents. Namely, periadolescence is classically defined as the ontogenetic period that encompasses the week preceding the onset of puberty and the first few days thereafter (Spear and Brake 1983). Periadolescent rodents differ markedly from adults in their spontaneous behavioral repertoire (Cirulli et al. 1996; Terranova et al. 1993; Meaney and Stewart 1981; Panksepp 1981). In fact, elevated levels of novelty seeking and a reduced behavioral and hormonal response to stress (Adriani et al. 1998; Adriani and Laviola 2000) are exhibited by animals around this age. A characteristic hyporesponsivity to the effects of an acute administration of psychostimulants (Spear and Brake 1983; Laviola et al. 1995; Bolanos et al. 1998; Adriani and Laviola 2000), a peculiar pattern of behavioral sensitization following repeated drug exposure (Laviola et al. 1995, 2001; Adriani et al. 1998), as well as a weak drug-induced place conditioning profile (Adriani et al. 1998; Bolanos et al. 1996, 1998; but see Campbell and Spear 2000), are also reported. Based on these findings, an increased vulnerability to the addictive properties of abused drugs has been suggested to be typical of adolescence in both humans and animals models (see Laviola et al. 1999).

In the present study, we were interested in nicotine, which beside being the main psychoactive compound implied in tobacco smoking, also shares most of the characteristics of other addictive drugs (Corrigall et al. 1992,1994; Pontieri et al. 1996; Merlo-Pich et al. 1997; Stolerman 1999). Nicotine's effects in mice have been shown to be highly dependent on the genetic background (see Marks et al. 1989; Robinson et al. 1996). However, the interaction between the pharmacological effects and the incentive properties of nicotine during the adolescent period has been largely neglected in basic research. In this view, an increasing interest emerged recently about the unique consequences of exposure to a potent psychoactive compound like nicotine during adolescence (see Kelley and Middaugh 1999; Trauth et al. 1999).

To study the voluntary consumption of abused drugs in laboratory settings, the most fruitful and reliable experimental paradigm is intravenous self-administration, where nicotine has been shown to serve as a reinforcer in a wide range of animal species (Goldberg et al. 1981; Spealman and Goldberg 1982; Risner and Goldberg 1983; for a review, see Goldberg et al. 1993; Rose and Corrigall 1997) including humans (Henningfield et al. 1983, 1985). To the same purpose, oral selfadministration schedules can be used. Animals are provided with the possibility of a free choice between two bottles, containing either a vehicle or a nicotine solution. The nicotine solutions generally fail to be preferred to water in this paradigm when the two bottles are left continously available $24 \mathrm{~h}$ per day (Le Houezec et al. 1989; Flynn et al. 1989). Results are negative in various rat and mouse strains, even when attempts have been made to try to mask the NIC bitter taste by means of a sweetened solution as a vehicle (Smith and Roberts 1995; Meliska et al. 1995; Robinson et al. 1996). A very recent study provided however evidence that a clear-cut preference for the nicotine bottle can be established in mice adapted to a water-deprivation schedule, and given a 2-h daily access to the two bottles (Adriani et al. 2002). The water-deprivation schedule adopted in the present study has already been described in the literature (Zimmerberg and Brett 1992). This procedure was chosen first with the aim of increasing animals' motivation to drink at the time of scheduled fluid availability. Second, such a procedure guaranteed a restricted availability of the drug (so that animals were under a 22-h drug abstinence period each day). Interestingly, it has been reported that, in oral self-administration paradigms, the variables that control animal behavior appear to be the same for all addictive drugs under conditions of limited access (see Meisch and Stewart 1994).

The first aim of the present experiment was to investigate patterns of voluntary nicotine consumption in mice during adolescence. The oral self-administration paradigm described above was chosen in order to overcome the methodological difficulties associated with the use of intravenous self-administration, which would hardly meet the needs of rapidly growing animals. Paying attention to available epidemiological data (see Discussion), the adolescent period (ranging from weaning to adulthood) was subdivided into three different developmental phases, namely Early (postnatal day (pnd) 24 to 35), Middle (pnd 37 to 48) and Late (pnd 50 to 61) adolescence. Mice were given a free choice between two bottles containing either tap water or a nicotine solution (see Adriani et al. 2002). An additional group, presented with two water-containing bottles, was also included in the design. This was aimed to control for a potential influence of nicotine on total fluid intake. A 
fading study was then performed: the concentration of nicotine in the solution was gradually decreased, to assess whether animals would actively increase their fluid intake in order to mantain a stable drug consumption. This procedure is currently adopted in intravenous self-administration studies (see Witkin 1994; Wise 1987; Weeks and Collins 1979) to evaluate the reinforcing properties of a given drug in a dose-response curve.

When performing studies on developing animals, one important point is that metabolism of a given drug could differ across different ages. Such a variable might affect the actual levels of the drug and of its active metabolites in the blood flow, which in turn might affect the drug consumption. The second aim of the present study was an assessment of potential age-related differences in the pharmacokinetics of nicotine. To this purpose, plasma levels of cotinine-the principal biomarker of nicotine consumption and tobacco exposure-were assessed. Even if there is no general agreement and possible limitations of this measure could be raised (see Discussion), cotinine levels have been reported to be linearly and directly related to daily available nicotine (Rama-Sastry et al. 1995; Rosa et al. 1992). The rate of body weight gain in these rapidly growing animals was also analyzed.

Finally, it could be argued that any drug solution is preferred over water because of its taste, rather than its post-oral pharmacological effects. In order to address this point, a number of methods could be used (for literature see Flynn et al. 1989; Berridge 2000). Among these possibilities, the assessment of behavioral pharmacological effects of oral nicotine was chosen. To this aim, a second experiment compared the pharmacological effects of nicotine on locomotor activity in Early and Late adolescent mice tested immediately after the drinking session.

\section{MATERIALS AND METHODS}

\section{Subjects}

Outbred CD-1 mice (25-28 g) purchased from Charles River Italia (Calco, Italy) were housed in an air conditioned room (temperature $21 \pm 1^{\circ} \mathrm{C}$, relative humidity $60 \pm 10 \%$, lights on from 8:30 P.M. to 8:30 A.M.) with water and pellet food (Enriched standard diet purchased from Mucedola, Settimo Milanese, Italy) being available ad libitum. An outbred strain was selected to increase the generalizability of the findings. Upon arrival, breeding groups were formed (one male with two females) and housed in Plexiglas cages $(33 \times 13 \times 13 \mathrm{~cm})$ with a sawdust bedding. After approximately two weeks, the male was removed and the females were housed individually and inspected daily for delivery. On pnd 1 (the day after delivery), litters were culled to three males and three females. Upon weaning (pnd 21), three mouse pups origi- nating from three different litters were housed per cage, segregated by sex.

\section{Experimental Procedure}

During the specific experimental age period, mice were adapted to a 22-h water deprivation schedule, that is, no bottles were available in the home cage (whereas food was provided ad libitum). For the daily 2-h drinking session, animals were gently picked up by the tail and placed individually in drinking cages (same size and shape as the home cage), whose standard cage tops accommodated two bottles (food pellets were available on the floor). After a first acclimation day (both bottles in the drinking cage containing water), the specific experimental procedure began. To monitor the effects of water deprivation and nicotine consumption, animals were weighed each day. In order to measure each animal's fluid intake, bottles were weighed before and after the drinking session. The weight loss due to leakage and evaporation was calculated from two identical bottles placed in an empty cage ("blank"), and subtracted from bottle weight data. This measure was however not supposed to take into account the leakage due to animals jostling against the bottles.

Experiment 1. According to a split-litter design, the three same-sex sibling animals coming from the same litter were separated and randomly assigned to be tested during one of three different age periods, namely Early adolescence (pnd 24 to 35), Middle adolescence (pnd 37 to 48 ) and Late adolescence (pnd 50 to 61). Each litter was randomly assigned to either the Nicotine ( $\mathrm{n}=9$ litters) or the Control ( $\mathrm{n}=5$ litters) group of the free-choice drinking study. When adapted to the water deprivation schedule (see above), animals within the Nicotine group were given ( $2 \mathrm{~h} /$ day for 12 days) a choice between two bottles containing either tap water or a nicotine $(10 \mathrm{mg} / \mathrm{l})$ solution (days 1 to 6). Animals in the Control group were exposed to the same 2-h drinking schedule, with the difference that both bottles contained tap water. To avoid a potential bias represented by an individual preference for either the right or the left side of the cage, the position of the nicotine-containing bottle at the beginning of the experiment was counterbalanced. Moreover, on Day 4 of the schedule, bottle positions were reversed, in order to leave out any potential spatial preference bias. With the aim of assessing whether animals would selfregulate for decreasing nicotine concentration, a fading study was also conducted, in which the nicotine concentration was reduced to $7 \mathrm{mg} / \mathrm{l}$ (days 7 to 9 ) and then to $5 \mathrm{mg} / \mathrm{l}$ (days 10 to 12 ).

A separate group of mice from the three age groups, adapted to a water deprivation schedule (as above), were allowed to drink ( $1 \mathrm{~h} /$ day for three days) from a bottle containing a nicotine $(10 \mathrm{mg} / \mathrm{l})$ solution. On the third day, 
animals were sacrificed at $0,40,80$, or 120 min following the end of the drinking session, for trunk-blood collection. Plasma samples were frozen at $-20 \mathrm{C}^{\circ}$ and stored for subsequent analysis in batches. Serum cotinine levels (Rosa et al. 1992) were measured in duplicate with the radioimmunoassay (RIA) described by Van Vunakis and colleagues (1993), using tritiated cotinine, antiserum raised in rabbits, and goat anti-rabbit $\gamma$ globulin, to separate antibody-bound cotinine from free analyte. In order to quantify cotinine, standards of 0.2 to $20 \mathrm{ng} / \mathrm{ml}$ were used. The limit of detection was $0.2 \mathrm{ng} / \mathrm{ml}$ and the interassay coefficient of variation was 6 to $10 \%$.

Experiment 2. According to a split-litter design, the three same-sex sibling animals coming from the same litter were randomly assigned to be tested with one of three different nicotine concentrations $(0,10$, or $30 \mathrm{mg} / \mathrm{l})$. Separate litters were assigned to be tested during Early or Late adolescence (pnd 24-25 and 50-51, respectively). When adapted to the water deprivation schedule (as above), animals were allowed to drink from a bottle containing the assigned solution. Following the 1-h drinking session, animals were immediately tested for locomotor activity.

The apparatus for this test consisted of an opaque plexiglas rectangular box with smooth walls, subdivided into two compartments $(20 \times 14 \times 27 \mathrm{~cm})$ connected by a door. Each compartment was provided with infrared photobeams, placed on the wall a few $\mathrm{cm}$ above the floor. Each beam interruption caused by a mouse was recorded by an IBM computer equipped with a specific custom-made software. The measure of crossing between compartments was obtained automatically. The whole session was automatically subdivided into 5-min intervals. Testing of different experimental groups was counterbalanced across time and the floor of the apparatus was washed after each animal was tested.

\section{Solutions}

The drug solution was prepared by dissolving nicotine ([-]-1-Methyl-2-[3-pyrityl] pyrrolidine) hydrogen tartrate (SIGMA) in tap water. All concentrations are expressed as nicotine base. To obtain the faded-out solutions, the initial solution was diluted with tap water. Nicotine concentrations were selected on the basis of literature data (Meliska et al. 1995; Robinson et al. 1996; Adriani et al. 2002).

\section{Statistics}

We adopted a split-litter design (Chiarotti et al. 1987), each litter representing the statistical unit. This procedure is widely requested and adopted in studies dealing with immature animals, where sibling pups within each litter are not independent (see Zorrilla 1997).
Experiment 1. Data were analyzed by means of a splitlitter ANOVA. To keep into account the fact that body weight changed dramatically in these rapidly growing animals, data for the actual analysis were obtained by dividing the absolute values of fluid intake by each animal's body weight. The general model was a 2 group (Control vs. Nicotine) $\times 2$ sex (female vs. male) $\times 3$ age (Early, Middle or Late adolescents) $\times 3$ days $\times 2$ solution (tap water vs. nicotine solution). Group variable was a between-litter factor; all other variables were within-litter factors. For the first six-day period of the experiment a 2-position (before and after the bottle positions were reversed) variable was used. For the fading procedure, a 3 dose (10, 7 or $5 \mathrm{mg} / \mathrm{l}$ nicotine) variable was used. Following a preliminary general ANOVA, the Control and the Nicotine groups were analyzed separately.

Experiment 2. Data were analyzed by means of a splitlitter ANOVA. The general model was a 2 age (Early vs. Late adolescents) $\times 2$ sex (female vs. male) $\times 3$ solution $(0,10$, or $30 \mathrm{mg} / 1$ nicotine solution). Age was a between-litter factor, all other variables were within-litter factors. Post-hoc comparisons were performed when allowed by using the Tukey HSD Test.

\section{RESULTS}

\section{Experiment 1}

Total Fluid Intake. Inspection of results in the preliminary general ANOVA indicated that the Control and Nicotine animals drank the same amount of fluid, i.e. the group variable was not significant $\left(\mathrm{F}_{1,12}=.16, \mathrm{~ns}\right)$. The finding of a main effect of $\operatorname{sex}\left(\mathrm{F}_{1,12}=20.84, p<.001\right)$ indicated that females drank in general more fluid than males. Fluid intake also differed as a function of age $\left(\mathrm{F}_{2,24}=13.42, p<.001\right)$, Early adolescents drinking more than the older subjects. Moreover, a sex $\times$ age interaction $\left(\mathrm{F}_{2,24}=3.92, p<.05\right)$ revealed that the sex difference emerged only after puberty, i.e. in Middle and Late adolescents (see Table 1). A similar profile was also evident during the fading study.

From this point onward, the two groups (Control vs. Nicotine) were not directly comparable since the main

Table 1. Mean ( \pm SEM) Daily Fluid Intake $(\mu \mathrm{l} / \mathrm{g}$ Body Weight) from Both Bottles during the First Six-day Period in Experiment 1.

\begin{tabular}{lcc}
\hline Age-groups & Males & Females \\
\hline Early adolescents & $178.6 \pm 6.7$ & $190.0 \pm 6.6$ \\
Middle adolescents & $151.5 \pm 4.5^{*}$ & $184.6 \pm 5.5$ \\
Late adolescents & $148.4 \pm 5.0^{*}$ & $177.9 \pm 4.8$ \\
\hline
\end{tabular}

In the absence of significant effects, data were collapsed over Control and Nicotine groups $(\mathrm{n}=14) .{ }^{*} p<.05$ in post-hocs between the two sexes. 
aim of the present experiment was to assess potential age-related differences in the preference for a nicotine over a water solution. Hence, following the preliminary general ANOVA, the Control and the Nicotine groups were analyzed separately. As expected, within the Control group, non-significant changes were found for the solution variable $\left(\mathrm{F}_{1,4}=.24, \mathrm{~ns}\right)$, and for the age $\times$ solution interaction $\left(\mathrm{F}_{2,8}=.92\right.$, $\left.\mathrm{ns}\right)$. Hence, no significant spatial preference bias was shown for any control bottle at any age.

Nicotine Preference. An ANOVA was carried out on data from the Nicotine group. In this analysis, the sex $\times$ solution and the age $\times$ sex $\times$ solution interactions did not reach significance. Interestingly, an age $\times$ solution interaction appeared $\left(\mathrm{F}_{2,16}=24.27, p<.001\right)$. Early adolescents showed a prominent and significant preference for the nicotine solution, which was however not evident in the older-age groups (see Figure 1). Moreover, the age $\times$ solution $\times$ position interaction was significant $\left(\mathrm{F}_{2,16}=4,79, p<.05\right)$. Multiple comparisons revealed that a preference for either bottle varied as a function of age. Specifically, for Early adolescent mice, the significant preference for the nicotine solution was stable also after the reversal of bottle position ( $p$ values $<$ .01 ). This finding allows us to conclude that the preference shown by mice was not due to a spatial preference bias but rather was a consistent phenomenon. No reliable or significant preference for any bottle appeared in the Middle adolescence group. Interestingly, for Late adolescents, a significant preference for the water bottle was found $(p<.01)$, which was however not stable since it disappeared after bottle reversal.

Fading Study. Within the Control group, no significant preference for any bottle at any age was found, the solution effect $\left(\mathrm{F}_{1,4}=.85, \mathrm{~ns}\right)$ and the age $\times$ solution interaction $\left(\mathrm{F}_{2,8}=.85, \mathrm{~ns}\right)$ both failing to reach significance (data not shown). Within the Nicotine group, however, the ANOVA yielded significance for the solution variable $\left(\mathrm{F}_{1,8}=5.59, p<.05\right)$ and for the age $\times$ solution interaction $\left(\mathrm{F}_{2,16}=8.81, p<.01\right)$. Multiple comparisons confirmed that a significant preference for the nicotine solution was only evident in Early adolescents $(p<.01)$, this preference being completely absent in older subjects (see Figure 2, upper panels).

Separate analyses performed within each age group confirmed and extended this picture. No main effects of the solution variable were significant for either Middle or Late adolescents $\left(\mathrm{F}_{1,8}=.52\right.$, and .22, respectively, $\left.\mathrm{ns}\right)$, thus confirming that animals at these older ages did not develop a specific preference for either bottle. Conversely, for Early adolescents, a significant main effect of solution $\left(\mathrm{F}_{1,8}=45.78, p<.001\right)$, and, more importantly, a dose $\times$ solution interaction $\left(\mathrm{F}_{2,16}=4.11, p<\right.$ $.05)$, appeared. Specifically, when comparing the $7 \mathrm{mg} /$ 1 to the $5 \mathrm{mg} / 1$ concentration, fluid intake from the water bottle appeared to be slightly decreased, whereas the corresponding intake from the nicotine bottle was somewhat increased.

This profile was confirmed by an ANOVA performed on day-by-day intake differences between the two bottles (i.e. nicotine bottle minus water bottle consumption, see bars in Figure 2, bottom panel). In this analysis, a main effect of dose $\left(\mathrm{F}_{2,16}=4.11, p<.05\right)$ and day $\left(\mathrm{F}_{2,16}=3.84, p<.05\right)$ were found. Specifically, a significant and prominent increase in the intake difference between the two bottles was evident two days after the passage from the 10 to the $7 \mathrm{mg} / 1$ concentration, and also two days after the passage from the 7 to the $5 \mathrm{mg} / 1$

\section{Early adolescents Middle adolescents Late adolescents}

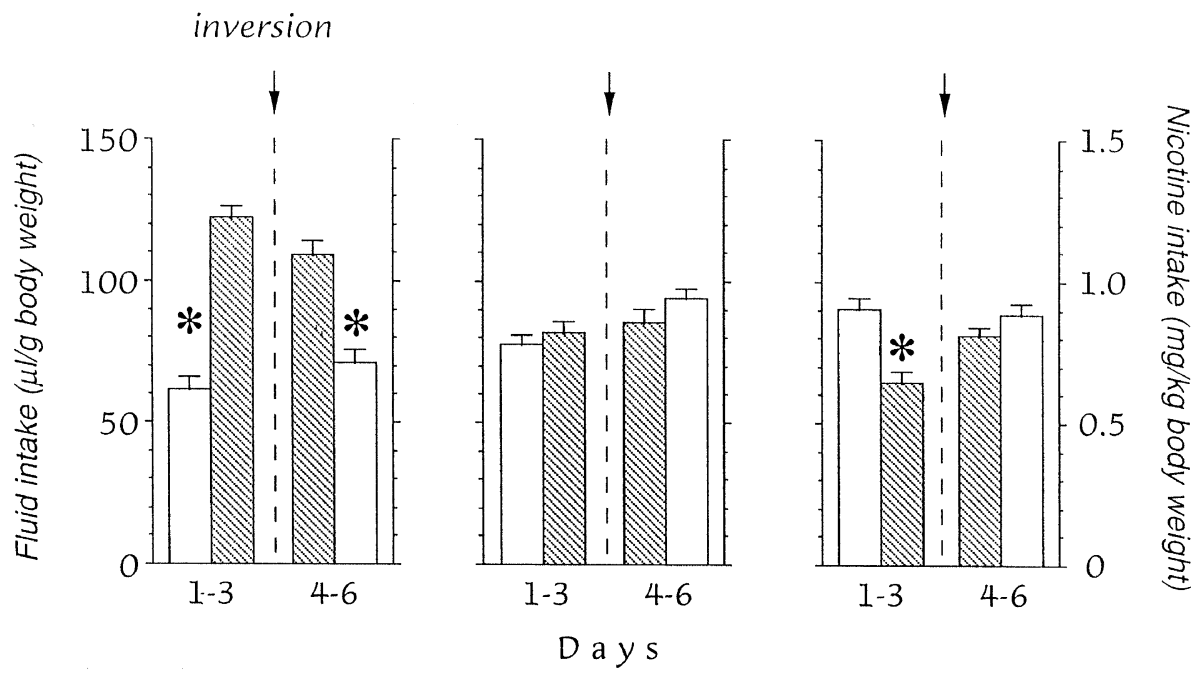

Figure 1. Mean fluid (see left $Y$-axis scale) and nicotine (see right $\mathrm{Y}$-axis scale) intake shown by mice allowed to choose between nicotine $(10 \mathrm{mg} / \mathrm{kg})$ and water, both before (days 1-3) and after (days 4-6) the reversal of bottle position (see arrow). Data are presented pooled over the 3-day periods. In the absence of any effect of the sex variable, data from males and females have been collapsed $(\mathrm{m}=18) .{ }^{*} p<.05$ in multiple comparisons between the two bottles. 
Early adolescents
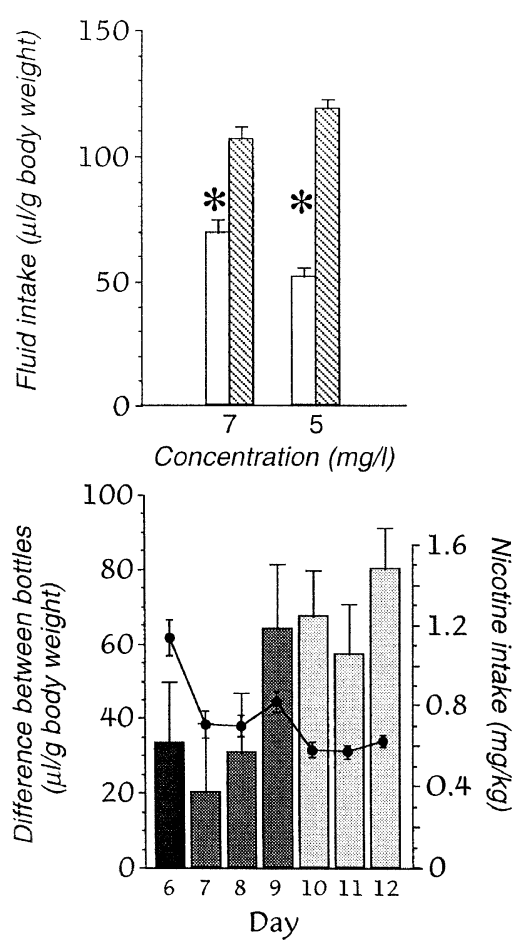

Middle adolescents Late adolescents
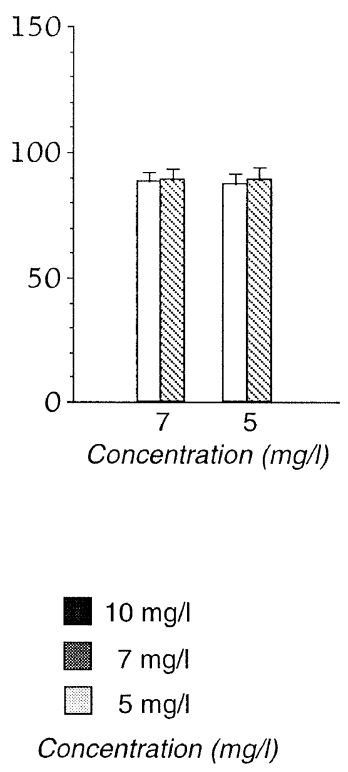
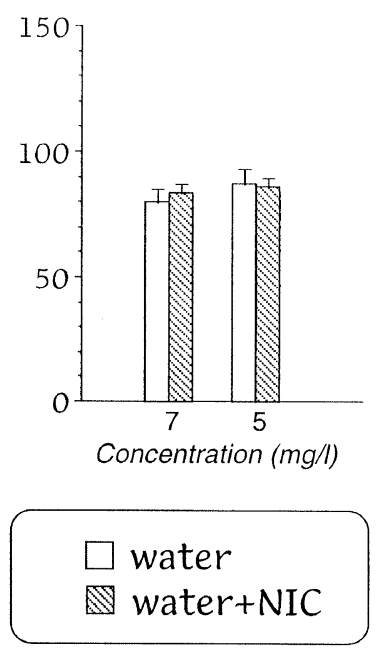

Figure 2. Upper panels: Mean fluid intake shown by nicotineexposed mice during the fading study. Nicotine concentration was reduced to $7 \mathrm{mg} / 1$ (days $7-9$ ) and then to $5 \mathrm{mg} / 1$ (days 10-12). Data are presented pooled over the 3-day periods. In the absence of any effect of the sex variable, data from males and females have been collapsed $(\mathrm{m}=18) .{ }^{*} p<.05$ in multiple comparisons between the two bottles. Lower panel: Difference of intake between the nicotine and the water bottle (see bars) and nicotine intake (see lines) shown by Early adolescents on separate days (6 to 12) during the fading study.

concentration $(p<.05)$. In Figure 2 (bottom panel, line graph) the nicotine intake by Early adolescent mice is also shown. ANOVA yielded a main effect of dose $\left(\mathrm{F}_{2,16}\right.$ $=74.8, p<.01)$. Multiple comparisons revealed that a significant decrease in nicotine intake was evident upon passage from the 10 to the $7 \mathrm{mg} / \mathrm{kg}$ concentration $(p<$ .05). Conversely, no significant differences in actual nicotine intake were found upon the passage from the 7 to the $5 \mathrm{mg} / \mathrm{kg}$ concentration.

Body Growth Rate. As expected, mice observed during adolescence were characterized by a rapid growth; thus it seemed important to analyze the rate of body weight gain during the experiment (see Figure 3 and its legend). Within the Early adolescent group, the growth curve was actually very steep, mean body weight being $15.4 \pm 0.4 \mathrm{~g}$ at the beginning and $24.4 \pm 0.7 \mathrm{~g}$ at the end of Early adolescence period (i.e., animals almost doubled their weight over two weeks). These data confirmed that a growth spurt is typical of subjects around this age. The ANOVA yielded a main effect of day $\left(\mathrm{F}_{6,72}=73.21\right.$, $p<.001)$. Specifically, as shown in Table 2 , a reduction of such a pronounced growth rate followed the first day of water deprivation. However, mice readily adapted to the schedule. As shown in Figure 3, their growth rate was very pronounced $(6.87 \pm 0.62 \%$ per day) for most of the experimental period, and then decreased dramatically (down to $1.99 \pm 0.21 \%$ per day). A main effect of $\operatorname{sex}\left(\mathrm{F}_{1,12}=19.19, p<.001\right)$, and a sex $\times$ day interaction $\left(\mathrm{F}_{6,72}=1.01, p<.01\right)$, were also found. Specifically, a dramatic decrease in growth rate was shown by pnd 30 in the female group, whereas elevated growth rates persisted until pnd 32 in males. Such a profile was possibly responsible for the higher absolute body weight shown by males, when compared with females.

Early adolescents showed a group $\times$ day interaction $\left(\mathrm{F}_{6,72}=2.93, p<.01\right)$ (see Figure 3, bottom panel). Specifically, the possibility of free drinking from the nicotine solution was associated with a significant elevation in growth rate in the Nicotine group on pnd 26. As a consequence, animals which had free access to nicotine weighed on average $3.4 \%$ more than Control animals at the end of their experimental period.

Middle adolescents, as shown in Table 2, underwent a significant decrease in body weight that was specifically associated with the first day of the water deprivation schedule (main effect of day, $\mathrm{F}_{6,72}=17.90, p<$ .001). Conversely, such a profile was not evident for Late adolescents (day, $\mathrm{F}_{6,72}=.81$, ns). When considering growth rate during the 12 -day experimental period, the profile appeared quite flat for both Middle and Late adolescents (see Figure 3), the growth-spurt being already over by this time. Absolute body weights were $27.1 \pm$ $0.7 \mathrm{~g}$ at the beginning of Middle adolescence and $31.0 \pm$ $0.9 \mathrm{~g}$ at the end of Late adolescence, mice gaining only $4 \mathrm{~g}$ over these four weeks. No significant effects of the group variable were found. Hence, the possibility of nicotine consumption did not affect body weight parameters in these two age groups.

Plasma Cotinine Levels. During the last drinking session, animals of the three ages showed a mean nicotine 
Early adolescents
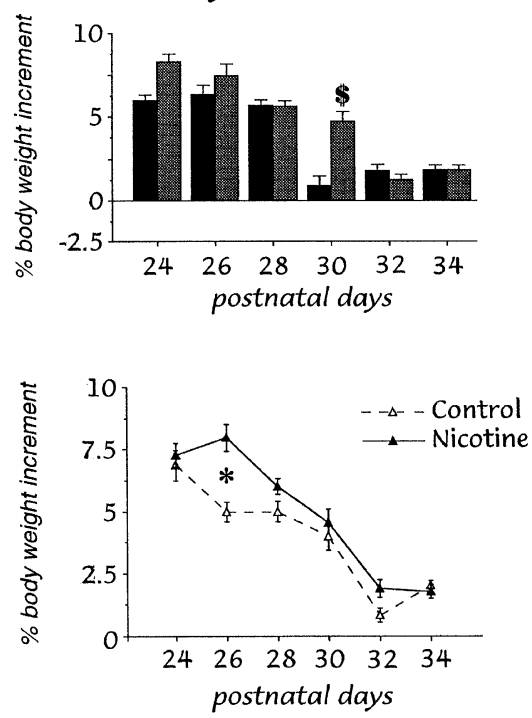

Middle adolescents

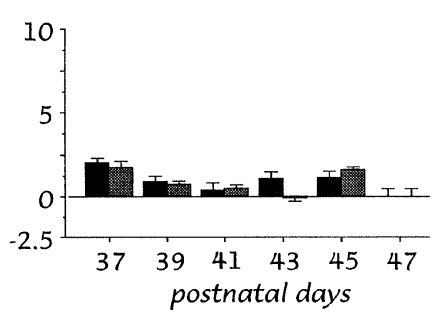

Late adolescents

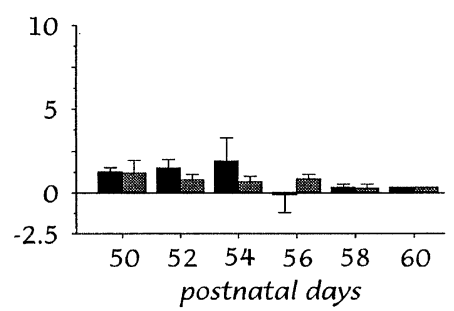

females

males

Figure 3. Upper panels: Growth rate in mice $(n=14)$ during the whole 12-day experimental period. The dependent variable was the daily percent increment of body weight. ${ }^{\$} p<.05$ in multiple comparisons between sexes. Lower panel: Effects of nicotine drinking on growth rate in the Early adolescent group (Data collapsed over sexes). ${ }^{*} p<.05$ in multiple comparisons between Nicotine $(n=18)$ and Control $(n=20)$ groups.

intake of $1.68 \pm .04 ; 1.40 \pm .04 ; 1.23 \pm .03 \mathrm{mg} / \mathrm{kg}$, respectively. The ANOVA performed on these data revealed a main effect of age $\left(\mathrm{F}_{2,60}=34.5, p<.001\right)$. Multiple comparisons indicated that nicotine intake slightly but significantly decreased as animals grew older.

As expected, plasma cotinine levels decreased regularly over time $\left(\mathrm{F}_{3,50}=28.09, p<.001\right)$. The age effect missed significance $\left(\mathrm{F}_{2,50}=2.46, p=.096\right)$, revealing only a slight tendency toward lower plasma cotinine levels in Late adolescent mice. Interestingly, the age $\times$ time interaction was not significant $\left(\mathrm{F}_{6,50}=0.19\right.$, ns), indicating that the time course profile of plasma cotinine did not differ in mice of the three ages (see Figure 4).

\section{Experiment 2}

Mean fluid intake and actual nicotine intake during the drinking session are shown in Table 3. As for fluid intake, the ANOVA yielded significance for the dose $\times$

Table 2. Mean ( \pm SEM) Body Weight Change (\%)

Following the First Day of the Two-hour Water Deprivation Schedule in Experiment 1.

\begin{tabular}{lcc}
\hline Age-groups & Males & Females \\
\hline Early adolescents & $+2.49 \pm .59$ & $+1.99 \pm .73$ \\
Middle adolescents & $-3.11 \pm .30$ & $-5.34 \pm .73$ \\
Late adolescents & $+1.75 \pm .41$ & $+1.77 \pm .70$ \\
\hline
\end{tabular}

In the absence of significant effects, data were collapsed over Control and Nicotine groups $(\mathrm{n}=14)$. age interaction $\left(\mathrm{F}_{2,20}=3.69, p<.05\right)$. Specifically, Early adolescent subjects drank significantly less nicotine solution than tap water at both concentrations. Conversely, no differences between nicotine solutions and tap water were evident for the older group.

As for nicotine intake, the ANOVA revealed a main effect of dose $\left(\mathrm{F}_{1,8}=616.7, p<.001\right)$. As expected, mice drinking from the highest concentration showed a 3-fold nicotine intake when compared with mice drinking from the lowest concentration. Interestingly, the dose $\times$

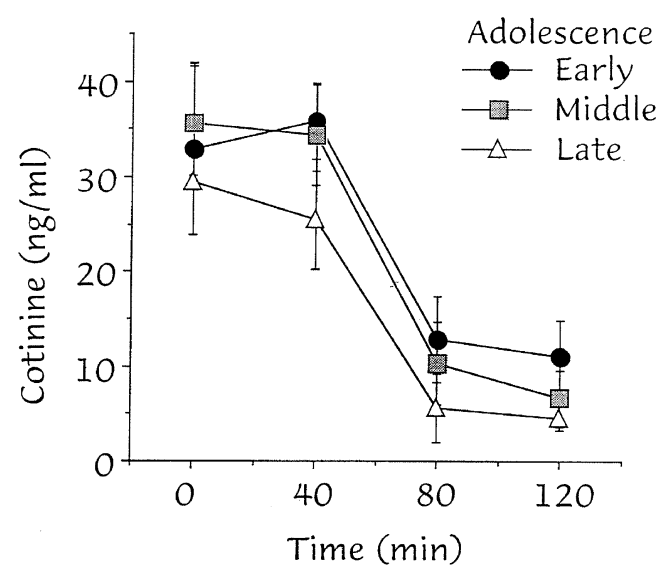

Figure 4. Plasma cotinine levels $(\mu \mathrm{g} / \mathrm{ml})$ in subjects of the three ages sacrificed at four different intervals following the end of the 1-h drinking session (Expriment 1). Animals were provided with a bottle containing a $10 \mathrm{mg} / 1$ nicotine solution for three days $(n=6)$. 
Table 3. Mean ( \pm SEM) Fluid Intake ( $\mu \mathrm{l} / \mathrm{g}$ body weight) and Nicotine Intake $(\mathrm{mg} / \mathrm{kg})$ During the One-hour Drinking Session in Experiment 2.

\begin{tabular}{lccccc}
\hline & \multicolumn{2}{c}{ Early adolescents } & & \multicolumn{2}{c}{ Late adolescents } \\
\cline { 2 - 3 } \cline { 5 - 6 } Concentration & Fluid & NIC & & Fluid & NIC \\
\hline Tap water & $129.3 \pm 8.6$ & 0 & & $94.6 \pm 11.4$ & 0 \\
$10 \mathrm{mg} / 1$ & $105.6 \pm 6.7 *$ & $1.06 \pm .07$ & & $107.0 \pm 13.1$ & $1.07 \pm .13$ \\
$30 \mathrm{mg} / 1$ & $101.1 \pm 5.0 *$ & $3.03 \pm .15$ & & $104.8 \pm 5.4$ & $3.13 \pm .16$ \\
\hline
\end{tabular}

In the absence of significant effects, data were collapsed over sexes ( $\mathrm{n}=$ 6). ${ }^{*} p<.05$ in post-hocs between the nicotine solutions and tap water.

age interaction was not significant $\left(\mathrm{F}_{1,8}=0.34, p=.57\right.$, $\mathrm{ns})$, revealing that animals of the two ages showed a similar intake of nicotine at both dosages.

As for data about the number of crossings (see Figure 5 ), the ANOVA yielded significance for the age $\times$ dose interaction $\left(\mathrm{F}_{2,20}=7.08, p<.01\right)$, revealing that the effects of oral nicotine on locomotor activity were age-dependent. Specifically, post-hoc comparisons revealed that Early adolescents allowed to drink a nicotine solution showed a higher number of crossings than controls. Conversely, upon the same dosage, older mice showed a reduction in the number of crossings, when compared with controls. In the presence of a similar actual drug intake across the ages, these results indicate that nicotine's behavioral effects were quite opposite in the two age groups.

\section{DISCUSSION}

Despite the social and scientific importance of a better understanding of the determinants of drug use during

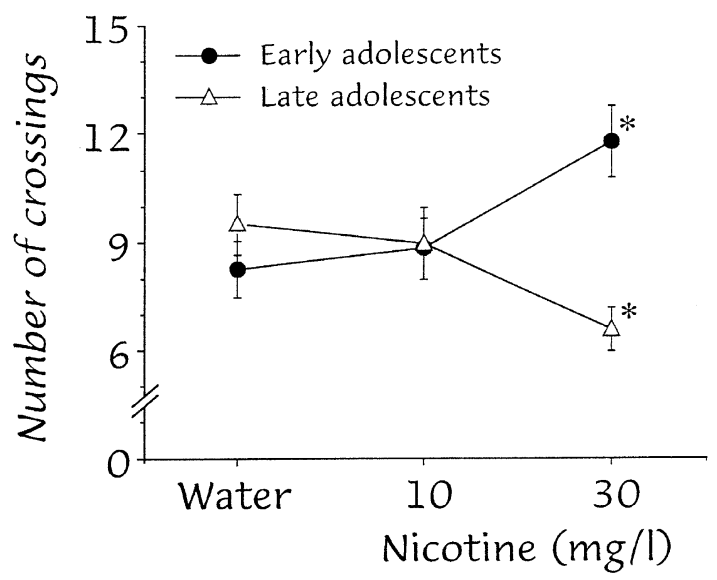

Figure 5. Number of crossings shown by Early adolescent or Late adolescent mice, immediately following the end of the 1-h drinking session (Experiment 2). Animals were provided with a bottle containing a nicotine (NIC, 0,10 or $30 \mathrm{mg} / \mathrm{l}$ ) solution $(n=6)$. In the absence of any effect of the sex variable, data from males and females have been collapsed. ${ }^{*} p<.05$ when compared with the water-drinking control group. adolescence, the patterns of voluntary consumption during this developmental phase have been poorly investigated in laboratory settings (see Ferris et al. 1998; Kelley and Middaugh 1999). Data from the present study represent one of the first attempts in this direction, and the main results can be summarized as follows:

1. Early adolescents showed a significant preference for the nicotine solution over water, which remained prominent and stable during the whole 12-day-long experimental period. Conversely, subjects from older ages did not show any preference for either bottle.

2. When the nicotine concentration was gradually reduced in the fading study, a consistent increment in fluid intake from the nicotine bottle was exhibited by Early adolescents, together with a decreased intake from the water bottle. Conversely, older subjects did not modify the level of fluid consumption from either bottle.

3. The time-course profile of plasma cotinine levels indicated that nicotine metabolism was somewhat accelerated in younger animals. Moreover, drinking a nicotine solution resulted in a prominent hyperactivity in Early adolescents, whereas it produced hypoactivity in older subjects.

In the present study, a clear-cut preference for nicotine was shown by mice during Early adolescence. These subjects drank significantly more from the bottle containing the nicotine solution than from the bottle containing tap water only. This preference was already evident on the first day of the schedule in Experiment 1, and was consistently maintained during the whole 12day-long testing period, even when the positions of the two bottles were reversed. This allows us to rule out the possibility that the preference for the nicotine bottle was due to a spatial preference bias. During the fading study (when the nicotine concentration was gradually reduced), Early adolescents showed a slight increment of fluid consumption from the nicotine bottle, along with a decreased intake from the water bottle. When considering as a whole the 9-day-long fading period, an initial drop in actual drug consumption followed the first drug fading (from 10 to $7 \mathrm{mg} / \mathrm{l}$ ). A day-by-day inspection of data better clarified that the intake difference between the two fluids increased significantly over time. Animals seemed to need two days to adapt to the new situation, and exhibited a steep increment in the intake-difference between the two fluids on the third day after the change. A similar profile was evidenced upon the following step in nicotine fading (from 7 to $5 \mathrm{mg} / \mathrm{l}$ ). As a whole, these data seem to suggest that a behavioral strategy was adopted by animals to cope with the changes in drug availability, that is, they tried to drink more nicotine solution and less water (for a similar profile, see also Adriani et al. 2002). Additional nicotine concentrations should perhaps have been 
tested to represent a more complete dose-response curve. Nevertheless, it might be suggested that Early adolescent mice tried to self-regulate to overcome the drop in nicotine concentration (see Wise 1987; Witkin 1994; Weeks and Collins 1979).

Although it seems intuitively unlikely, it could be argued that the nicotine solution was preferred over water by Early adolescents because of its taste, rather than its post-oral pharmacological effects. Nicotine solutions are generally reported to be bitter. In laboratory rats, however, nicotine is reported to elicit aversive responses (as assessed in the taste-reactivity test) only when the concentration is around $50 \mathrm{mg} / 1$ or more (Flynn et al. 1989). At lower concentrations, the acute reaction to the taste of nicotine is reported to be "neutral." It has also been shown that, following a period of free-choice drinking between nicotine and water, a nicotine solution is able to elicit more ingestive responses than tap water, suggesting an increase in the immediate palatability of nicotine (Flynn et al. 1989). From these results, authors have concluded that nicotine palatability is enhanced because of its pairing with positive post-oral reinforcement, a similar result being also evident with morphine solutions (Zellner et al. 1985). The specific role of taste factors could have been investigated more deeply by assessing the reaction to quinine, a well-known bitter agent (see also Berridge 2000, for a review).

On the first day of exposure in Experiment 1, that is, before any post-oral reinforcement could take place, Early adolescent mice already exhibited a clear-cut preference for the nicotine solution under free-choice conditions. Conversely, when a single bottle was available in Experiment 2, Early adolescent subjects exhibited significantly less drinking if the bottle contained nicotine, than if it contained tap water. This general profile was not unexpected, due to relevant differences between the two experiments (i.e. the number of bottles and the time-length of exposure). First, it should be considered that the aim of the second experiment was to evaluate the psychopharmacological effects of oral nicotine consumption, and not profiles of preference or aversion. Moreover, since mice from the Experiment 1 had the possibility to drink also from a water bottle, they were probably allowed to operate a dilution of the bitter nicotine taste. In contrast, animals in Experiment 2 did not have such a chance, and hence a certain degree of avoidance toward nicotine was exhibited. A quite similar profile has been often reported with several psychoactive compounds, which are generally avoided in a forced-exposure condition, whereas they can be preferred in a free-choice setting.

Some considerations can be put forward. Forced exposure to novelty is generally stressful to rodents (Hennessy et al. 1979; Misslin et al. 1982), whereas, under free-choice conditions, periadolescent rodents are known to be characterized by a marked preference for novelty
(Adriani et al. 1998; Laviola et al. 1999; Spear 2000). Hence, it is possible to hypothesize that an age-related discontinuity in the response to the novel taste of nicotine emerged. Namely, Early adolescent mice in Experiment 1 were particularly attracted, during the first freechoice session, by the "novelty" associated with the nicotine taste. However, a "novelty-driven" preference would be expected to vanish over the following days. Yet, present results do indicate that such a preference was highly stable during the whole 12-day-long experiment. In agreement with the considerations put forward by other authors (Zellman et al. 1985; Flynn et al. 1989), it seems likely that, following the first drinking sessions, the taste of nicotine became also associated with post-oral reinforcement. As a consequence, the preference for the drug solution and its taste did not vanish. A broader range of nicotine concentrations should perhaps have been studied, since apparent drug peculiarities could also be dosespecific (Smith and Roberts 1995; Meliska et al. 1995; Robinson et al. 1996).

Interestingly, no significant preference for the nicotine solution was found in the two older-age groups. Actually, a significant aversion to nicotine was found in the case of Late adolescents during the first three days of the schedule. However, the latter effect was not robust, in that it disappeared when the positions of the two bottles were reversed. Such a finding suggests that the bottle reversal is a useful and necessary step to test the strength of any given preference, and provides further validation of the present experimental paradigm. The failure to find a significant preference for the nicotine solution over tap water in the older mouse groups apparently suggests that the drug was not able to produce any significant positive incentive property. Rather, Middle and Late adolescents appeared to drink from one bottle or the other at a chance level.

\section{Behavioral/Pharmacological Effects of Oral Nicotine}

To investigate whether drinking a nicotine solution was able to produce pharmacologically active plasma levels of this drug, two strategies were employed. Following the drinking session: (1) a time-course profile of plasma cotinine, which is the major metabolite of nicotine, was carried out; and (2) the modulatory effects of nicotine on locomotor activity patterns were assessed.

In the present study, following a 1-h drinking sessionduring which mice orally self-administered about 1.2 $1.5 \mathrm{mg} / \mathrm{kg}$ of nicotine-plasma levels of cotinine resulted to be around $20-40 \mathrm{ng} / \mathrm{ml}$, that is, between $20 \%$ and $33 \%$ of levels which are expected $1 \mathrm{~h}$ after a $1 \mathrm{mg} /$ $\mathrm{kg}$ i.p. administration of nicotine in mice $(60-200 \mathrm{ng} /$ $\mathrm{ml}$, see Petersen et al. 1984). It should be underlined that, in the present study, cotinine levels were measured at the end of a 1-h drinking session, and that higher levels might possibly have been reached during the drinking session itself. Nevertheless, present cotinine 
levels were virtually in agreement with a $0.2-0.3 \mathrm{mg} / \mathrm{kg}$ nicotine dose, administered i.p. in the middle of the drinking session. Since nicotine is known to be pharmacologically active at this dosage, it may be concluded that psychoactive levels of nicotine were reached in mice allowed to drink a nicotine solution.

Moreover, it should be noted that mice from the Early adolescent group showed a daily nicotine intake that is nicely comparable to those obtained with intravenous self-administration in adult rats (where drug consumption ranges from 0.5 to $1.5 \mathrm{mg} / \mathrm{kg}$ per daily session, see Corrigall and Coen 1989; Donny et al. 1995; Shoaib and Stolerman 1999). Also, present plasma levels of cotinine were in the range of those resulting from nicotine smoking in humans $(15-40 \mathrm{ng} / \mathrm{ml}$; Feyerabend et al. 1985; Russell et al. 1982). As a whole, literature data and present results do suggest that nicotine can produce pharmacologically active plasma levels via the oral route.

A possible limitation of the cotinine measure could be that small differences in nicotine metabolism across groups could produce relatively large differences in plasma cotinine. Interestingly, whereas Early adolescents showed the highest levels of nicotine intake, similar plasma levels of cotinine were found across ages, thus indicating that nicotine metabolism was somewhat accelerated at a younger age. Thus, the possibility that a peculiar preference for the nicotine solution (shown by Early adolescents) might be due to an age-related differential availability of the drug in the blood cannot be ruled out. However, an increased motivation toward the seeking for drugs has been associated with adolescence in mice. This is possibly based on an age-related peculiar interaction between the elevated search for novel stimuli and the sensitivity of the brain reward systems (for a review, see Laviola et al. 1999; Spear 2000).

In Experiment 2, mice drinking from the bottle with the high drug-concentration showed a 3-fold nicotine intake when compared with mice drinking the low drug-concentration. Interestingly, animals of the two ages showed a quite similar intake of nicotine at both dosages, yet oral nicotine affected locomotor activity in quite opposite ways in the two age groups. Indeed, as a consequence of drinking from a nicotine solution, locomotion was increased in Early adolescents, and conversely reduced in older subjects. Interestingly, druginduced increases in locomotion have been considered as an indirect index of reward (Wise and Bozarth 1987). Previous studies assessing the acute effects of i.p. nicotine administration upon locomotion have yielded mixed results (either an increase or a decrease have been reported, see Jerome and Sanberg 1987; Clarke and Kumar 1983). Present data suggest an age-related dissociation in nicotine effects, which can possibly be ascribed to age-related discontinuities in the functional maturation of drug-targeted brain systems (Naeff et al. 1992; Teicher et al. 1995; Trauth et al. 1999). Such data serve to confirm that nicotine is able to reach sensitive brain pathways and to modulate levels of locomotion in mice, i.e. this drug is pharmacologically active, when self-administered via the oral route.

\section{Fluid Intake and Body Growth Rate}

When considering the total fluid intake from both bottles in Experiment 1, a significant sex-difference appeared within the two older-age groups, with females drinking more fluid than males. The expression of such a sex difference was probably the consequence of a significant decrease in fluid intake shown by male mice entering the Middle adolescence phase (for literature and discussion on the differential effects of sex hormones on drinking behavior, see Fernandez-Trisac et al. 1998; Vijande et al. 1978). As for body growth rate, Early adolescent mice were associated with elevated levels of daily body-weight gain, which eventually decreased later on (by pnd 30 for females and by pnd 32 for males), as a possible consequence of the onset of puberty. The possibility of drinking nicotine was also associated with a slight elevation of the growth rate in Early adolescents. Even if obtained on water-deprived subjects, this finding seems in contrast with the bulk of the literature on adult subjects, nicotine administration being generally associated with a loss of body weight (see e.g. McNair and Bryson 1983; Grunberg et al. 1987). Consistently, a similar result has been recently reported in adolescent female rats (Faraday et al. 2001). Again, present data may perhaps represent a paradoxical effect of the developmental exposure to this drug.

\section{CONCLUSION}

Present results can be compared with epidemiological data, reporting that human adolescents smoke fewer cigarettes but experience significantly higher rates of dependence than adults (Kandel and Chen 2000). An early onset of cigarette use is actually a strong predictor of an elevated risk to develop dependence later in life (Taioli and Wynder 1991; Breslau et al. 1993), and of a subsequent failure to quit (Nides et al. 1995). Indeed, the likelihood of spontaneous cessation of smoking habits is extremely low among people who started smoking before 13 years of age (Breslau and Peterson 1996). These data also seem to suggest a peculiar vulnerability to nicotine in peripubertal human adolescents. A nice correlation between the animal model and the human case might thus be suggested. Indeed, in the present study, vulnerability to nicotine was exhibited by mice around Early adolescence, that is, during the developmental phase just preceding puberty.

A peculiar age-related behavioral as well as neurobiological condition has been suggested to be typical of 
adolescence. Specifically, an age-related elevation in novelty-seeking (see Adriani et al. 1998; Spear 2000), which is known to be a risk factor for vulnerability to drugs of abuse (see Bardo et al. 1996), may account for the early onset of nicotine preference shown by mice in the present study. More work would be needed to further characterize, in laboratory rodents, the patterns of spontaneous consumption of drugs of abuse during adolescence (see e.g. Ferris et al. 1998), as well as the possible long-term consequences of such exposure (see e.g. Kelley and Middaugh 1999).

\section{ACKNOWLEDGMENTS}

This research was supported as part of the intramural grant to G.L., Research Project on "Psychobiological risk or protection factors for behavioral disorders and vulnerability to recreational substances abuse during development," Nervous and Mental Disorders Research Area, Istituto Superiore di Sanità, Italy, and by the "Fondo Nazionale per la Lotta alla Droga," Ministero per la Solidarietà Sociale, Italy. W.A. was supported by a "Giuseppe LEVI" bursary from the Accademia Nazionale dei Lincei, Italy. We wish to thank Flavia Chiarotti for statistical advice, Augusto Vitale for critical reading, and Angelina Valanzano for expert technical assistance.

\section{REFERENCES}

Adriani W, Chiarotti F, Laviola G (1998): Elevated novelty seeking and typical d-amphetamine sensitization in periadolescent compared to adult mice. Behav Neurosci 112:1152-1166

Adriani W, Laviola G (2000): A unique hormonal and behavioral hyporesponsivity to both forced novelty and d-amphetamine in periadolescent mice. Neuropharmacology 39:334-346

Adriani W, Macrì S, Laviola G (2002): Nicotine oral selfadministration in mice: Individual differences and influence of type of vehicle. Behav Brain Res (in press)

Arnett J (1992): Reckless behavior in adolescence: A developmental perspective. Dev Rev 12:339-373

Anthony JC, Petronis KR (1995): Early-onset drug use and risk of later drug problems. Drug Alcohol Depend 40:9-15

Bardo MT, Donohew RL, Harrington NG (1996): Psychobiology of novelty seeking and drug seeking behavior. Behav Brain Res 77:23-43

Berridge KC (2000): Measuring hedonic impact in animals and infants: Microstructure of affective taste reactivity patterns. Neurosci Biobehav Rev 24:173-198

Bolanos CA, Garmsen GM, Clair MA, McDougall SA (1996): Effects of the kappa-opioid receptor agonist U-50488 on morphine-induced place preference conditioning in the developing rat. Eur J Pharmacol 317:1-8

Bolanos CA, Glatt SJ, Jackson D (1998): Subsensitivity to dopaminergic drugs in periadolescent rats: A behavioral and neurochemical analysis. Developmental Brain Research 111:25-33
Breslau N, Peterson EL (1996): Smoking cessation in young adults: Age at initiation of cigarette smoking and other suspected influences. Am J Public Health 86:214-220

Breslau N, Fenn N, Peterson EL (1993): Early smoking initiation and nicotine dependence in a cohort of young adults. Drug Alcohol Depend 33:129-137

Campbell JO, Spear LP (2000): Cocaine and morphineinduced place conditioning in adolescent and adult rats. Physiol Behav 68:487-493

Chiarotti F, Alleva E, Bignami G (1987): Problems of test choice and data analysis in behavioral teratology: The case of prenatal benzo-diazepines. Neurotoxicol Teratol 9:179-186

Cirulli F, Terranova ML, Laviola G (1996): Affiliation in periadolescent rats: Behavioral and corticosterone response to social reunion with familiar or unfamiliar partners. Pharmacol Biochem Behav 54:99-105

Clarke PBS, Kumar R (1983): The effects of nicotine on locomotor activity in non-tolerant and tolerant rats. $\mathrm{Br} \mathrm{J}$ Pharmacol 78:329-337

Colby SM, Tiffany ST, Shiffman S, Niaura RS (2000): Are adolescent smokers dependent on nicotine? A review of the evidence. Drug Alcohol Depend 59:S83-S95

Corrigall WA, Coen KM (1989): Nicotine mantains robust self-administration in rats on a limited-access schedule. Psychopharmacology (Berl) 99:473-478

Corrigall WA, Franklin KBJ, Coen KM, Clarke PBS (1992): The mesolimbic dopaminergic system is implicated in the reinforcing effects of nicotine. Psychopharmacology (Berl) 107:285-289

Corrigall WA, Coen KM, Adamson KL (1994): Self-administered nicotine activates the mesolimbic dopamine system through the ventral tegmental area. Brain Res 653:278-284

Donny EC, Caggiula AR, Knopf S, Brown C (1995): Nicotine self-administration in rats. Psychopharmacology (Berl) 122:390-394

Faraday MM, Elliott B, Grunberg NE (2001): Nicotine's biobehavioral actions differ in adult vs. adolescent rats. Pharmacology Biochemistry and Behavior 70:675-689

Fernandez-Trisac JL, Brime JI, Lopez-Sela P, Sanchez-Garrido L, Costalees M, Arguelles J, Vijande M (1998): Effects of castration and gonadal hormones on insulininduced drinking. Pharmacol Biochem Behav 59:521-526

Ferris CF, Shtiegman K, King JA (1998): Voluntary ethanol consumption in male adolescent hamsters increases testosterone and aggression. Physiol Behav 63:739-744

Feyerabend C, Ings RMJ, Russell MA (1985): Nicotine pharmacokinetics and its application to intake from smoking. Br J Clin Pharmacol 19:239-247

Flynn FW, Webster M, Ksir C (1989): Chronic voluntary nicotine drinking enhances nicotine palatability. Behav Neurosci 103:356-364

Goldberg SR, Spearman RD, Goldberg DM (1981): Persistent behavior at high rates mantained by intravenous selfadministration of nicotine. Science 214:573-575

Goldberg SR, Spealman RD, Risner ME, Henningfield JE (1993): Control of behavior by intravenous nicotine injections in laboratory animals. Pharmacol Biochem Behav 19:1011-1020

Grunberg NE, Winders SE, Popp KA (1987): Sex differences in 
nicotine's effects on consummatory behavior and body weight in rats. Psychopharmacology (Berl) 91:221-225

Hennessy MB, Heybach JP, Vernikos J, Levine S (1979): Plasma corticosterone concentrations sensitively reflect levels of stimulus intensity in the rat. Physiol Behav 22:821-825

Henningfield JE, Miyasato K, Jasinski DR (1983): Cigarette smokers self-administer intravenous nicotine. Pharmacol Biochem Behav 19:887-890

Henningfield JE, Miyasato K, Jasinski DR (1985): Abuse liability and pharmacodynamic characteristics of intravenous and inhaled nicotine. J Pharmacol Exp Ther 234:1-12

Jerome A, Sanberg PR (1987): The effects of nicotine on locomotor behavior in non-tolerant rats: A multivariate assessment. Psychopharmacology (Berl) 93:397-400

Kandel DB, Chen K (2000): Extent of smoking and nicotine dependence in the United States: 1991-1993. Nicotine and Tobacco Research 2:263-274

Kelley BM, Middaugh LD (1999): Periadolescent nicotine exposure reduced cocaine reward in adult mice. J Addict Dis 18:27-39

Laviola G, Wood RD, Kuhn C, Francis R, Spear LP (1995): Cocaine sensitization in periadolescent and adult rats. J Pharmacol Exp Ther 275:345-357

Laviola G, Adriani W, Terranova ML, Gerra G (1999): Psychobiological risk factors for vulnerability to psychostimulants in human adolescents and animal models. Neurosci Biobehav Rev 23:993-1010

Laviola G, Pascucci T, Pieretti S (2001): D-amphetamineinduced behavioural sensitization and striatal dopamine release in awake freely-moving periadolescent rats. Pharmacol Biochem Behav 68:115-124

Le Houezec J, Martin C, Cohen C, Molimard R (1989): Failure of behavioral dependence induction and oral nicotine bioavailability in rats. Physiol Behav 45:103-108

Marks MJ, Stitzel JA, Collins AC (1989): Genetic influences on nicotine responses. Pharmacol Biochem Behav 33: $667-678$

Mathias R (1996): Students' use of marijuana, other illicit drugs, and cigarettes continued to rise in 1995. NIDA Notes 11:8-9

McNair E, Bryson R (1983): Effects of nicotine on weight change and food consumption in rats. Pharmacol Biochem Behav 18:341-344

Meaney MJ, Stewart J (1981): A descriptive study of social development in the rat, Rattus norvegicus. Anim Behav 29:34-45

Meisch RA, Stewart RB (1994): Ethanol as a reinforcer: a review of laboratory studies of non-human primates. Behav Pharmacol 5:425-440

Meliska CJ, Bartke A, McGlacken G, Jensen RA (1995): Ethanol, nicotine, amphetamine and aspartame consumption and preference in CS7BL/ 6 and DBA/ 2 mice. Pharmacol Biochem Behav 50:619-626

Merlo-Pich E, Pagliusi SR, Tessari M, Talabot-Ayer D, Hooft van Huijsduijnen R, Chiamulera C (1997): Common neural substrates for the addictive properties of nicotine and cocaine. Science 275:83-86

Misslin R, Herzog F, Koch B, Ropartz P (1982): Effects of isolation, handling and novelty on the pituitary-adrenal response in the mouse. Psychoneuroendocrinology 7: 217-221

Naeff B, Schlumpf M, Lichtensteiger W (1992): Pre- and postnatal development of high affinity $\left[{ }^{3} \mathrm{H}\right]$ nicotine binding sites in rat brain regions: An autoradiographic study. Developmental Brain Research 68:163-174

Nides MA, Rakos RF, Gonzales D, Murray RP, Tashkin DP, Bjornson-Benson W, Lindgren P, Connett JE (1995): Predictors of initial smoking cessation and relapse through the first two years of the Lung Health Study. J Consult Clin Psychol 63:60-69

Panksepp J (1981): The ontogeny of play in rats. Dev Psychobiol 14:327-332

Petersen DR, Norris KJ, Thompson JA (1984): A comparative study of the disposition of nicotine and its metabolites in three inbred strains of mice. Drug Metabol Disposition 12:725-731

Pontieri FE, Tanda G, Orzi F, Di Chiara G (1996): Effects of nicotine on the nucleus accumbens and similarity to those of addictive drugs. Nature 382:255-257

Rama-Sastry BV, Chance MB, Horn JL, Janson VE (1995): Distribution and retention of nicotine and its metabolite, cotinine, in the rat as a function of time. Pharmacology 50:128-136

Risner ME, Goldberg SR (1983): A comparison of nicotine and cocaine self-administration in the dog: Fixed-ratio and progressive-ratio schedules of intravenous drug infusion. J Pharmacol Exp Ther 224:319-326

Robins LN, Przybeck TR (1985): Age of onset of drug use as a factor in drug and other disorders. In Jones CL, Battjes RL (eds), Etiology of Drug Abuse: Implications for Prevention. NIDA Research Monograph 56: 178-192

Robinson SF, Marks MJ, Collins AC (1996): Inbred mouse strains vary in oral self-selection of nicotine. Psychopharmacology (Berl) 124:332-339

Rosa M, Pacifici R, Altieri I, Pichini S, Ottaviani G, Zuccaro PG (1992): How the steady-state cotinine concentration in cigarette smokers is directly related to nicotine intake. Clin Pharmacol Ther 52:324-329

Rose JE, Corrigall WA (1997): Nicotine self-administration in animals and humans: Similarities and differences. Psychopharmacology (Berl) 30:28-40

Russell MA, Sutton SR, Iyer R, Feyerabend C, Vesey CJ (1982): Long-term switching to low tar, low nicotine cigarettes. Br J Addict 77:145-158

Shoaib M, Stolerman IP (1999): Plasma nicotine and cotinine levels following intravenous nicotine self-administration in rats. Psychopharmacology (Berl) 143:318-321

Smith A, Roberts DCS (1995): Oral self-administration of sweetened nicotine solutions by rats. Psychopharmacology (Berl) 120:341-346

Spealman RD, Goldberg SR (1982): Mainteinance of schedulecontrolled behavior by intravenous injections of nicotine in squirrel monkeys. J Pharmacol Exp Ther 223:402-408

Spear LP (2000): The adolescent brain and age-related behavioral manifestations. Neurosci Biobehav Rev 24:417-463

Spear LP, Brake SC (1983): Periadolescence: Age-dependent behavior and psychopharmacological responsivity in rats. Dev Psychobiol 16:83-109 
Stolerman IP (1999): Inter-species consistency in the behavioural pharmacology of nicotine dependence. Behav Pharmacol 10:559-580

Taioli E, Wynder EL (1991): The importance of age of starting smoking. N Engl J Med 325:968-969

Teicher MH, Andersen SL, Hostetter JC (1995): Evidence for dopamine receptor pruning between adolescence and adulthood in striatum but not nucleus accumbens. Developmental Brain Research 89:167-172

Terranova ML, Laviola G, Alleva E (1993): Ontogeny of amicable social behavior in the mouse: Gender differences and ongoing isolation outcomes. Dev Psychobiol 26:467-481

Trauth JA, Seidler FJ, McCook EC, Slotkin TA (1999): Adolescent nicotine exposure causes persistent upregulation of nicotinic cholinergic receptors in rat brain regions. Brain Res 851:9-19

Van Vunakis H, Gijka HB, Langone JJ (1993): Radioimmunoassay for nicotine and cotinine. In Seifert B, Van de Wiel HJ, Dodet B, O'Neill I.K. (eds), Enviromental Carcinogens: Methods of Analysis and Exposure Measurements, IARC Scientific Publications 109: 293-299

Vijande M, Costales M, Schiaffini O, Marin B (1978): Angio- tensin-induced drinking: Sexual differences. Pharmacol Biochem Behav 8:753-755

Weeks JR, Collins RJ (1979): Dose and physical dependence as factors in the self-administration of morphine by rats. Psychopharmacology (Berl) 65:171-177

Wise RA (1987): Intravenous drug self-administration: A special case of positive reinforcement. In Bozarth MA (ed), Methods of Assessing the Reinforcing Properties of Abused Drugs. New York, Springer, pp 117-142

Wise RA, Bozarth MA (1987): A psychomotor stimulant theory of addiction. Psychol Rev 94:469-492

Witkin JM (1994): Pharmacotherapy of cocaine abuse: Preclinical development. Neurosci Biobehav Rev 18:121-142

Yamaguchi K, Kandel DB (1984): Patterns of drug use from adolescence to young adulthood. III. Predictors of progression. Am J Public Health 74:673-681

Zorrilla EP (1997): Multiparous species present problems (and possibilities) to developmentalists. Dev Psychobiol 30:141-150

Zimmerberg B, Brett MB (1992): Effects of early environmental experience on self-administration of amphetamine and barbital. Psychopharmacology (Berl) 106:474-478 